\section{CLINICAL CASES FROM WARDS AND OUT-PATIENTS'.}

\author{
By JOHN A. RYLE, \\ M.D., \\ Assistant Physician to Guy's Hospital.
}

OF the four cases to be describled hereunder the earlier three have recently provided material for discussion at post-graduate demonstrations given in conjunction with my colleagues, Dr. A. F. Hurst and Dr. C. P. Symonds. The points which emerged at these discussions may help to illuminate the bare records of clinical history and physical findings. The instructive features of the fourth case will be manifest in the narrative.

Case 1.-E. B., male, aged 20, a clerk, was admitted to the ward for breathlessness. My house physician asked me to see him as an urgency, and was chiefly concerned on account of certain pulmonary signs which were then a prominent feature. There was a history of rheumatic fever at the age of 7 . Eighteen months previously the patient had been discharged from a Territorial unit on account of an hremoptysis. One aunt died of pulmonary tuberculosis. $\mathrm{He}$ had remained well until a week prior to his admission, when he developed cough, breathlessness, and loss of appetite: He stayed away from work for two days complaining of weakness, and was more comfortable sitting up. He also had a transient attack of pain in the right hypochondrium and said that he had lost weight slightly during the previous month.

On admission, there was orthopnœa, slight dyspnœa with a respiration rate of 24-30, slight pyrexia, pallor, and barely perceptible cyanosis. At both bases there was marked impairment of note with crepitations. The apices were clear. On the strength of the family history, the past hæmoptysis, the recent loss of weight and slight pyrexia my house physician had feared acute pneumonic tuberculosis. $\mathrm{His}$ anxiety was increased by a very rapid pulse. However, the patient's demeanour was curiously untroubled, and apart from the orthopnœa there was no distress, There was no œdema or palpable enlargement of the liver. His pulse-rate was i70 to the minute and regular.

This at once suggested a diagnosis of paroxysmal tachycardia, and I could not conceive that a patient with a pulmonary infection extensive enough to 'cause so rapid a pulse could look and feel so little like a dying man. The pulse-rate remained high without new symptoms for the next four days. This rapid and sustained pulse-rate without arrhythmia suggested the possibility of auricular flutter. An electrocardiogram (Dr. J. M. H. Campbell) on October II, 1927 , showed auricular flutter with 2 : I heartblock. Auricular rate 336 , ventricular rate I68. An initial treatment with digitalis ( $m \times v$ of the tincture t.i.d.) had the apparent effect of reducing the ventricular rate, but a further electrocardiogram on October 14 showed the auricular rate to be still 336 , with degrees of heart-block varying from $2: \mathbf{I}$ to $3: \mathbf{I}$ and $4: \mathbf{I}$. The pulmonary signs remained and a small effusion developed at the left base. After an interval digitalis was again given in doses of $m x$, four-hourly. On October 21, a further electrocardiogram showed that auricular fibrillation was established. On October 22 the pulse at the wrist was regular, and between 60 and 70 per minute. On October 25 the electrocardiogram showed restoration of normal rhythm. From this time onwards the lung signs quickly cleared. Seen later at OutPatients', a slow regular pulse was maintained, and the man was free from symptoms. Only after the return to a normal rhythm did a cardiac murmur, præsystolic in time, become audible.

The sequence of evcnts would appear to have been rheumatic fever at seven; myocarditis and mitral endocarditis; later mitral stenosis giving rise to a single hamoptysis; and finally development of auricular flutter. Clinically the important feature was the pulse. It is doubtful whether any pulse-rate so rapid, regular and sustained and accompanied by so little evidence of serious disease apart from pulmonary congestion, could be otherwise accounted for than by some form of paroxysmal tachycardia. A regular tachycardia with a rate between I20-160 per 
minute which persists for a long period and does not end spontaneously generally means auricular flutter. Simple paroxysmal tachycardia in which auricle and ventricle beat at the same rate is usually more transitory and starts and ends abruptly and spontaneously. Auricular flutter rarely stops withont treitment. In about $5^{\circ}$ per cent. of all cases of flutter fibrillation can be brought about with the aid of digitalis, and if the drug be then discontinued there is a reversion to normal rhythm. The differential diagnosis in cases of this kind may be from pneumonia or other acute pulmonary disease, but a finger on the wrist should suggest the diagnosis, particularly if the aspect of the patient at first suggests no serious illness. The pain under the right ribs was probably due to acute hepatic engorgment. From the clinical point of view it is interesting to note that with the ventricular rate reduced to 70 per minute the congestive signs at the base still persisted unchanged until after the restoration of normal rhythm. Without the assistance of the electrocardiogram the final disappearance of these signs might reasonably have been interpreted as indicating a restoration of normal auricular behaviour, but it would have been quite impossible to gauge the correct moment for discontinuance of the digitalis and to control the treatment with such nicety.

Case 2.-W. A., male, aged $3^{8}$, was admitted for "weakness" and a history of tarry motions. He had served in the East during the war, but had had no dysentery or malaria. Three years previously he was for a time troubled with nausea and vomiting. Eighteen months ago he contracted gonorrhœa. For six months he had been complaining of "rheumatic pains" in the occipital and temporal regions, and these were always worse at night. Eight weeks before admission he felt suddenly faint, and afterwards passed a black stool. This history clearly suggested bleeding from a gastric or duodenal ulcer, but did not explain the other symptoms. No indisputable evidence of ulcer was obtained while he was in the ward. Physical examination showed a pale, unhealthy man, slight below his natural weight. Excepting for the nocturnal headaches he was free from pain. There was slight intermittent pyrexta. The most noticeable finding was a coßsiderable enlargement of the liver, whige seemed to be irregularly divided into two $\mathrm{gr}$ three prominences by intervening depresssions. Otherwise its surface was smooth there were no bosses suggesting malignaft metastases. The edge was ill-defined. TH户 organ moved well on inspiration, and was visibly as well as palpably enlarged. The was a secondary anæmia with a hæmoglobị figure of $5^{\mathrm{I}}$ per cent. and 3,500,000 redt cells. As alternative possibilities cirrhos aınœbic hepatitis and malignant disease $\overrightarrow{\mathrm{f}}$ the liver were discussed in turn, but $t_{0}^{:}$: absence of any alcoholic history or apper ance, of any history of dysentery or hepa $\vec{z}$ pain, and of jaundice, leucocytosis a. wasting were advanced as arguments againgt all of these. A strong plea was put in for gummatous enlargement of the liver on alges grounds: (I) Of the nature of the enlakges-5 ment and the apparent deformity of athe liver; (2) the nocturnal headaches, whinch were strongly suggestive of syphilis. The blood gave a positive Wassermann reaction and with full doses of potassium iodide, increasing to I dr. three times a day, the e followed within a fortnight a complete dişappearance of the headache, a cessation fff the slight pyrexia, a voluntary statemenit from the patient that he had not felt so wefl for over a year, and a recession of the live: margin to the extent of at least three inche

Among the lessons of the case are the following:-

(I) A symptom-namely, nocturnal head ache-at first sight unconnected with the main physical finding, hepatic enlargements directed attention to the probable cause of the enlargement.

(2) Pyrexia is a not uncommon accon paniment of disease of the liver, whether cirrhotic, syphilitic or malignant.

(3) A leading symptom for which the patient sought advice, namely, melæn $\bar{\Phi}_{\text {, }}$ remained unexplained, but was probably do to an acute duodenal ulcer which had unde $\overrightarrow{\mathbb{P}}$ gone spontaneous healing. 
Case 3.-A boy, aged I4, was seen at OutPatients' and admitted to the ward with a history of hæmatemesis. $\mathrm{He}$ was of healthy family, had had pneumonia at the age of 7 , and for an indefinite period had suffered from headaches and looked anæmic.

Three months previously he suddenly vomited a large quantity of blood and was admitted to the local hospital, where he lay dangerously ill for many days. During convalescence he developed ascites which disappeared spontaneously. The boy admitted to no symptoms but was evidently anæmic. In the left upper quadrant of the abdomen protruding from below the rib margin there was a large tumour extending as low as the umbilical level. Its surface was smooth, its breadth below the ribs equal to four fingers, its edge rounded and less defined than is usually the case with splenic tumours. It was also strikingly less mobile than the majority of enlarged spleens, ascending and descending very little with the respiratory movements. Nevertheless, it was generally agreed that it was a large spleen. There was no demonstrable ascites and the physical examination was otherwise negative.

Blood examination resulted as follows: Hæmoglobin, 56 per cent.; red cells, 4,000,000; colour index, 0.7 ; white cells, 4,740; polymorphs, 60 per cent. ; eosinophils, 4.5 per cent.; lymphocytes, 24 per cent. ; hyalines, I I per cent. ; basophils, $0^{\circ} 5$ per cent.; clotting-time $3 \frac{3}{4}$ minutes (normal); fragility of red cells normal. Van den Bergh's test, negative, direct and indirect. The levulose test showed " appreciable hepatic deficiency." The history of hæmatemesis in a child in association with a big spleen, an anæmia of the secondary type, and a leucopænia, all supported a diagnosis of splenic anamia. The levulose test, the transient ascites and the hæmatemesis itself all suggested involvement of the liver in the cirrhotic process which affects this organ in the later phase of splenic anæmia.

The chief question for discussion was that of treatment. In appropriate cases it is generally agreed that splenectomy offers the best prospect of a restoration to health. Although no guarantee can be given that removal of the spleen will arrest the pro- gress of the hepatic cirrhosis, many cases of apparently complete recovery are on record.

What are the contra-indications to splenectomy?

The most important is the presence of adhesions between the spleen and the abdominal wall, rendering difficult and dangerous an operation which it is necessary to perform quickly and with as little bleeding as possible. In this case the immobility of the spleen and its unusually rounded border suggested that it had become attached to the anterior abdominal wall by adhesions following upon the ascites recorded during convalescence from the hæmorrhage. Operation was, therefore, not advised. The ultimate prognosis remains bad and treatment must be limited to a sheltered life and symptomatic measures for the anæmia. Deep $\mathrm{X}$-ray treatment is being given to the spleen.

Case 4.-Nurse $\mathrm{X}$, aged 27, was healthy until five years ago, when she had erysipelas during the first year of her training. After this she began to have attacks of griping pain in the left iliac fossa with vomiting. The attacks came at intervals of two or three weeks and lasted a few days. In 1924 she had a year's intermission. In 1925, while working at a chest hospital, she had similar attacks, was operated upon, and, according to her statement, an abnormal appendix and some caseous glands were removed. In December, 1925, she took up light duties at a sanatorium, and after an attack of abdominal pain with sore throat she developed diarrhœa. In April, 1926, she was still having abdominal pain and diarrhœa. A further operation was advised. She was admitted to a local hospital, but discharged herself. She was then, at her own request, admitted as a patient to another sanatorium, where she lost weight. Diarrhœa and abdominal pain continued, and there was pyrexia. In September, 1926, a serond laparotomy was performed, but nothing was found to account for her symptoms. On admission to Guy's Hospital in December, 1926, she was found to be passing from four to seven loose stools a day, and stated that she had passed blood and mucus. She 
seemed much concerned about the possibility of tuberculosis. Her chart showed frequent pyrexial spikes between $99^{\circ}$ and ro ${ }^{\circ}$, usually in the evening. She had been prepared for a sigmoidoscopy before the occasion of my first visit, and so, contrary to usual custom, I "examined her with the instrument before conducting a clinical survey. I noted that the appearances were not those of an ordinary ulcerative colitisthe diagnosis with which she had been admitted--but that the mucosa was moist, red, and slightly œdematous, as though she had had some irritating injection into the bowel. No ulcers but a few small hæmorrhagic spots were seen. Later, on my visits to the ward, I noticed that her respirations were always quick and shallow, the rate varying from 22-40 per minute. As there was no evidence of pulmonary or cardiac disease, and the rate was normal during sleep, I told her to stop this trick, and she did so. It was observed by the Sister that she was always suspicious and querulous, and did not co-operate with the nurses. I saw several specimens of stools. These were brown and watery, with a very small amount of mucus and occasionally-one or two isolated streaks of blood. Finding no adequate cause for the pyrexia, I asked for special care to be observed in the taking of the temperature. The nurses were "almost sure" that she could not have "faked" her temperature. However, one day she was caught with the stopper out of her hotwater bottle, and the temperature, which had been shown to be high, was immediately re-taken, and found to be normal. I then told the patient that I was going to have all her belongings searched by the Sister in my presence. An envelope full of purgative pills and a safety razor were found. After removal of the pills she immediately became constipated for the first time.

Diagnosis: Fictitious dyspnoea, pyrexia, and ulcerative colitis.

The patient expressed herself as unwilling to remain any longer in the hospital, and after a corrective talk was discharged.

The chief lesson of this case, perhaps, is the inadvisability of operating and re-operating for abdominal pain in young women.

\section{EDITORIAL NOTES. $\underset{-\infty}{\stackrel{\circ}{\stackrel{\circ}{*}}}$}

IT is with mourning and even, if the truth must be told, with moaning that we recopd the death of Sir Dawson Williams $\frac{\Phi}{\phi^{n}}$ February 27, yet, having a retrospect \&f his fine life, it is with a sense of exulfation also. In our last number we referred to his qualities as an editor and man off science on the occasion of his retireme $8 \mathrm{t}$ from the Editorship of the British Mediç Journal. Now we think of him as the vecty humane man. In a word, the arrestives feature of our memory of him is his tenderheartedness-always there and yet maskegr sometimes, as in the case of the stern Roman parent disporting himself, it may be, wi his children in the guise of a bear-skin atfid voice and all, only that the fierce-eyedness was never very successfully feigned. Bens ficiaries ourselves of his active practica sympathy in times of stress we gladly testimony (mostly perhaps for our ơ comfort) to the helpfulness of his gru零gentleness, and we here and now (again fegr our own heart's sake) express our gratitudf. In our last issue we referred to the pepmanence of his influence (and not to his only), and it will prove, we foretell, that thait influence will be obvious for many years $\underline{\underline{5}}$. come, while it will be pervasive for always. The Gods bury their workmen but carry क्रा their work.

We deeply regret to record the death, at sadly early age, of Mr. Basil Lang, a brillia surgeon of the Royal London Ophthalma Hospital, and son of Mr. William Lang, who for so many years was a tower of strengt on the acting staff of the same hospital, fro而 its Moorfields days.

Although, as we believe, our co-operation of associated Hospitals in London, with unrivalled opportunities of contact with case 